\title{
Call for Special Issue Papers: Exposure to Violence in Early Childhood
}

\author{
Deadline for Manuscript Submission: October 15, 2020
}

\author{
Guest Editors: Debra Niehoff, PhD; The Association for Frontotemporal Degeneration \\ Catherine Bradshaw, PhD; University of Virginia and Johns Hopkins School of Public Health
}

Child abuse and neglect are a pervasive public health problem. Data from the U.S. Administration for Children and Families show that in 2018, 678,000 children in the U.S. were victims of childhood maltreatment, resulting in an estimated 1,770 fatalities, with children under one year of age experiencing the highest rate of victimization. ${ }^{1}$ In addition to being victims themselves, children are also exposed to violence indirectly as witnesses of family and community violence.

Experiencing or observing violence as a child has an enduring impact on brain development and physical health that results in an increased risk of a wide range of psychological and somatic disorders, including aggressive and violent behavior by former victims. Understanding the long-term biological and psychosocial consequences of exposure to violence in childhood is therefore critical not only to the assessment of and response to violent offenders but also to the development of scientifically informed treatment and prevention strategies.

Violence and Gender invites manuscript submissions related to the full spectrum of outcomes following direct or indirect exposure to violence during early childhood, which we define as from birth to age 8. Examples of relevant research topics include, but are not limited to:

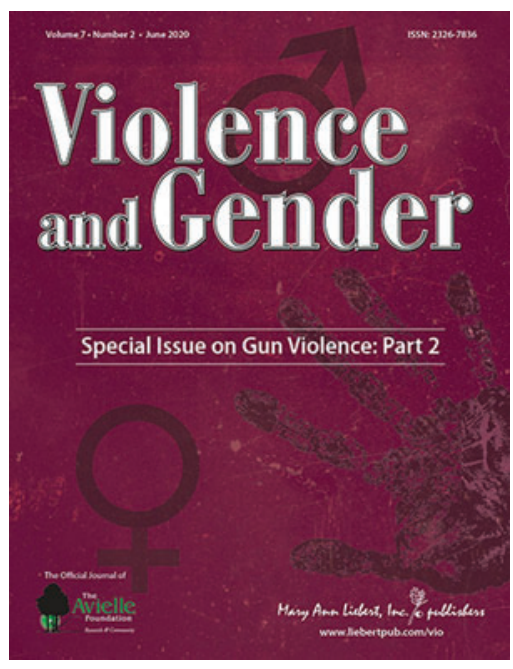

- Effects of childhood abuse and related adverse experiences on brain development

- Alterations to brain structure, cognitive function, or physiological stress responses in adults with a history of childhood abuse or neglect

- Recognition of physical, verbal, emotional, or sexual abuse by caregivers and others

- Risk factors for childhood abuse and neglect

- Behavioral outcomes in victims of childhood abuse

- Childhood exposure to violence and the development of somatic disorders

- Gender differences in biological and behavioral responses to abuse

- Factors promoting resiliency to the adverse effects of early-life abuse

- Evidence-based interventions for prevention and treatment

Original research articles, reviews, or perspectives will be considered. All manuscripts must be submitted online using the manuscript submission portal by October 15, 2020 and will undergo rigorous peer review following submission.

Queries to the editors to propose a topic prior to submission are encouraged. Please contact special issue editors Dr. Debra Niehoff or Dr. Catherine Bradshaw or Managing Editor Karen Cloud-Hansen to initiate your query.

Visit the Violence and Gender website to learn more, read past issues, and view author submission guidelines.

\section{Visit the Instructions for Authors: www.liebertpub.com/vio Submit your paper for peer review online: https://mc.manuscriptcentral.com/vio}

\footnotetext{
${ }^{1}$ U.S. Department of Health \& Human Services, Administration for Children and Families, Administration on Children, Youth and Families, Children's Bureau. (2020). Child Maltreatment 2018. Available from https://www.acf.hhs.gov/cb/research-data-technology/ statistics-research/child-maltreatment
}

Mary Ann Liebert, Inc., publishers, 140 Huguenot Street, New Rochelle, NY 10801, USA. 